\title{
EL LISOZIMA EN EL TRACTO DIGESTIVO DEL RECIEN NACIDO Y LACTANTE
}

\author{
Prof. H, VACCARO, Dres. J. CABEZAS Y D. COPAJA \\ Cáredra de Banteriologia e Inmunología de la Univissidad de Chile.
}

\section{CONCEPTOS GENERALES SOBRE EL LISOZIMA}

Entre los factores inespecificos de defensa más ampliamente distribuídos, merece consideración especial el principio inhibidor y lítico que fué descrito por primera vez por Alexander Fleming.

Este autor, partiendo de las investigaciones de Laschtschenko (1909) y de Rettger y Sperry (19.12), logró. continuándolas, verificaciones reveladoras, las que publicó, en i 922 , en un trabajo acerca del poder bactericida de la clara de huevo. (24)

Un año más tarde amplía sas estudios en colaboración con Allison (25), llegando les dos autores a identificar un principio bactericida de naturaleza enzimática, al cual denominan "Lisozima". Demostraron que dicho principio inhibidor y lítico se hallaba presente en la casi tetalidad de los humores y tejidos del organismo humano y animal. Del mismo modo comprobaron su presencia en algunos tejidos vegetales.

Este principio producía la inhibición o la lisis de numerosas especies bacterianas, saprófitas y patógenas.

El Lisozima contenido en la clara de huevo, fué el que sirvió a Fieming y Allison para estudiar su poder bactericida. Una dilución de clara de huevo al $1 \%$. mezciada, an partes iguales, con una emulsión microbiana concentrada de Micrococcus lysodeikticus, y colocada a una temperatura cercana a los 50 grados. produjo la lisis total de la emulsión bactérica antes de medio minuto, como se demostró mediante los 
exámenes directos y los cultivos practicados, que fueron. persistentemente negativos. La adíción de una gota de clara de huevo a un cultivo de 24 borks de aquella misma especie bacteriana, sembrada en placa de Petri, produjo el aclaramiento completo del medio en 1 minuto a la temperatura de 37 grados.

El Micracoccus lysodeikticus demóstró ser tan altamenté sensible, que diluciones de clara de huevo del 1 por cincuenta millones. produjeron su lisis total después de 24 horas a la temperatura de 37 grados.

Estos investigadores demostraron la presencia de este principio lítico, en la casi totalidad de las secreciones y excreciones del organismo humano, como ser: lágrimas, mucus nasal, saliva, líquido pleural, líquido ascítico y de hidrocele, semen, suéro sanguineo, secreciones vaginales, loquios, ete. Así mismo, lo contenían algunos productos patológicos: pus. orina albuminúrica o purulenta, 'líquidos de quistes, etc.

También los tejidos humanos demostraron contenerlo y entre éstos se distinguieron por un alto contenìdo lisozímico. la fibrina y una muestra de cartílago articular de la rótula.

El tejido cerebral lo contenía en proporciones inferiores a las meníngeas.

Los huevors de distintas especies de peces y sobre tódo los huevos de sollo, contendrían en alta proporoión el principio lítico de Fleming.

Fleming y Allison hicieron un estudio comparativo del Lisczima contenido en la clara de huevo de distintas especies de aves: gallinas, patas, tordos y nevatillas y compruebay, que la clara de huevo de gallina es la que contiene la más alta concentración lisozímica, siguiendo en importancia, la clar: de huevo de pata.

Norman J. Miller y Francis Mc Donald (26) en 1933. investigan el Lisozima en las leches de: mujer, mona, perra, gata, ratona y liama, comprobando su presencia en todas cllas y encontrando una concentración casi idéntica.

La leche de vaca, según J. y M. Bordet (27), careceria de este principio: Blatt y Kess:er, en 1937, llegan a la misma conclusión.

Prickett y colaboradores, en 1933, demuestran, por el contrario, que la leche de vaca contiene Lisozima.

Nuestros trabajos concordantes con lo verificado por Rosenthal y Lieberman (28) en 1931, nos han demostrado persistentemente 19 ausencia de Lisozima en la leche de vaca. 
Las leches de: coneja, cabra, oveja, cuyes, contendrían muy escasa cantidad de este principio, llegando en determinadas ocasicnes a carecer totalmente de él.

No contendrían Lisozima, según Fleming y Anlliscon. el liquido céfalo raquídeo, el sudor, la orina y deposiciones normales.

Según Goevaerts, el líquido amniótico carece de lisozima.

Bardet, en 1928. demostró que el sudor humano es capaz de producir la lisis de las bacterias sensibles al Lisozima.

Nuestros trabajos en curso, coinciden con la opinión de Bordet. La sarcina test, especie microbiana altamente sensible al Lisozima, que nosotros hemos empleado en todos nuestros trabajos acerca del contenido lisozímico en los distintos humores y secreciones, ha sido lizada con facilidad por el sudor humano. Algunas especies patógenas, tales como: Escherichia coli, Staphylococcus, Streptococcus viridans y haemolyticus han sido, en mayor o menor grado, inhibidas en su desarrollo.

\section{NATURALEZA QUMMICA Y PROPIEDADES}

Wolff (29), en 1927; Meyer y colaboradores (30), en 1936: Roberts (31), en 1937, y Abraham (32), en 1932, son los investigadores que en forma más completa se han preccupado del problema de la naturaleza química del Lisozima.

Abraham obtuvo este principio a partir de la clara de huevo, en forma de un polvo blanco desecado en acetona y éter, con una actividad de alrededor de dos mil unidades por miligramo y un peso molecular de aproximadamente 18,000. que contenía $\mathrm{N} \cdot 16,4 \%$. $\mathrm{S} 3,2 \%$, calculado sobre una hase de cenizas libres. Qbtuvo un producto amorfo, y otto cristalizado, con semejante grado de actividad.

El análisis cuantitativo verificado de la substancia amor$\mathrm{fa}$, demostró que ésta contenía los siguientes ámino-ácidos: Arginina $11,6 \%$. Cistina $7 \%$, Lisina $5,8 \%$, Tirosina 4,4 \% e Histidina 2,6\%.

El Lisozima obtenido y purificado por Meyer y colaboradores, en 1936, que se considera como una de las pre paraciones de más alta pureza, es un cuerpo de naturaleza básica, soluble en medio acuoso, acidificado e insoluble en los disolventes orgánicos puros en los medios alçaíinos. 
Su análisis centesimal, demostró lo siguiente:

C: $49.65 \% ; \mathrm{N}: 15.33 \%$; H: 6.44\%; P: $0.25 \%$; S: $0.64 \%$ : Cenizas: $3.3 \%$.

Su peso molecular aproximado fué de 25,000. I.as reacciones de Biuret, ácido glioxílico, fenol Greenberg y $\mathrm{ni}$ troprusiato de sodio, fueron positivas. La reacción de Moelisch fué siempre negativa. El ácido tricloroacético y el sulfosalicílico, no precipitaban sus diluciones, el ácido tungstico lo hizo incompletamente! El ácido perclórico y las sales de oro y plata, junto con precipitarlo, inactivaban el Lisezima.

El Lisozima se demostró como muy estable al calor y al ácido; así el ácido acético al $2 \%$ a 100 grados C., no afectó 1 poder lítico de este principio, después de 45 minutos de contacto.

En medio alcalinc; a la temperatura ambiente, se disminuía notablemente la actividad lítica del Lisozima antes de los 10 minutos. De acuerdo con la totalidad de las investigadores, consideramos que en un medio neutro, se evidencia el optimo de la actividad lisozímica.

En $\mathrm{pH}$ ácido, la solución lisozímica atraviesa cien faciiidad la bujía Berkefeld 5. mientras que a $\mathrm{pH}$ neutro lo hace con surma dificultad. Los filtros de porcelana, algodón y rapel retienen el Lisozima, mientras no han sido saturados, después de lo cual el elemento los atraviesa con facilidad. No dializa. Se comporta como un coloide electro positivo

Es absorbido por el carbón vegetal, caolín. celulosa, pere no por el hidróxido de aluminio coloidal, hidróxido de hierro coioidal y fosfato tricálcico. Su tamaño molecular sería infcrior a 30 milimictones. Es destruído por la luz ultervioleta.

Respectc de su estabilidad, las soluciones de Lisozima, conservan su actividad, ya a la temperatura de la estufa o del frigidaire, pot un tiempo más o menos largo. El yodo y el ćxido cuproso. lo inactivan, fenómenos que son parcialmente reversibles.

Lcs fermentos proteolíticos digestivos no disminuyen el poder bacteriolítico del Lisozima contenido en la clara de huevo. Los distintos antisépticos se comportan de modo variable. Mientras que algunas, come el fenol al $1 \%$, sublimado oxicianuro de mercurio al 1 por mil y el mentol al 1 por 10 mil, no modifican en absoluto el poder lítico de1 Lisozima, la tintura de yodo a concentraciones que no determinan la precipitación de este producto, inhiber totalmente su actividad inhibidor lítica. Los compuestos.. sulfamidados. 
asociados al Lisozima, parecen reforzar su acción cuando llegan a coritacto con especies microbianas sensibles.

\section{MECANISMO DE ACCION DEL LISOZIMA}

Fleming y Allison consideraron el Lisozima como una diastasa, sin llegar a demostrar su calidad enzimática ni el substrato sobre el cual ejerce su acción.

Hallauer (33) creyó que dicha acción se ejercia sobre la fracción mucoide de la membrana microbiana, ya que el ferómeno lítico va acociado con un aumento del $\mathrm{N}$ no proteico, de $\mathrm{P}$ inorgánico y de substancias reductoras de origen protoplasmática que han sido puestas en libertad gracias a la desintegración de dicha membrana.

K. Meyer, J. W. Palmer y R. Thompson (30) apoyan la teoría físico química del mecanismo de acción del Lisozima, considerándolo como capaz de praducir el descenso de la tensión superficial, opinión que ha quedado totalmente desvirtuada gracias a múltiples investigaciones en las cuales se ha probado que las substancias que disminuyen la tensión superficial en forma manifiesta - coma el alcohol caprílico que la hace descender en un $60 \%$ en relación con la del agua destilada-, no se comportan en absoluto como agentes Jíticos.

Wolff y Kiwasawa, en 1927, comprobaron que el $\mathrm{I}$ i sozima altamente purificado, disuelto en agua o en suero fisiológico, no hacia descender la tensión superficiar.

K. Meyer y colaboradores, siguiendo los trabajos de Fleming y Allison y especialmente los de Hallauer, que consideran la acción del Lisozima como un fenómeno diastásico que se verifica sobre la fracción mucoide de la membrana microbiana, lograron localizar en determinados eslabones azucarados el sitio en que la desintegración se ejercía.

Estos autores, colocando al Lisozima purificado frente a determinados substratos, no lograron comprobar de su parte la calidad de proteasa, quinasa, amilasa, lipasa ni fosfatasa.

L. A. Epstein y. E. Chain (34), en 1940, aceptan que el Lisozima actúa como una diastasa capaz de hidrolizar determinados polisacáridos contenidos en el cuerpo de las especies microbianas sensibles, polisacárido insoluble en el agus, responsable del mantenimiento de la estructura morfológica de las bacterias. 
En los casos en que este pctisacárido es el único elemento mantenedor de dicha estructura, las especies microbianas sensibles al Lisozima, puestas a su contacto, son desin. tegradas hasta su completa lisis. Pero, cuando están presentes también otras estructuras, el Lisozima tendría sobre las especíes sensibles sólo un pcoder bacteriostático, o bien bactericida, ya que dicho polisacárido desempeñaría, aparte de intervenir en la mantención de la estructura morfóógica, un rol de vital importancia para la bacteria.

Según lo establecen Epstein y Chain, el pclisacárido que lograron aistar de cuerpos secos de Micrococcus lysodeikticus y que demostró tener un alto peso molecular, puesto a contacto con el Lisozima purificado de la clara de huevo o de otras fuentes que lo contienen, permitió ubicar a esta subsstancia en el grupo de las carbohidrasas.

La hidrolisis obtenida en un $\mathrm{pH}$ entre 2 y 9 , daría crigen, entre ctras substancias, a una $\mathrm{N}$-áminoexosa acetilada y una queto exosa, no ccpnsiguiéndose demostrar la presencia de otros hidratos de carbono.

En resumen, los estudios realizados acerca del mecanismo de acción del Lisozima frente a las especies microbianas sensibles, saprófitas y patógenas, a pesar de no haber resuelto el problema en forma definitiva. permiten, gracias a las recientes verificaciones de Meyer y colaboradores, considerar a esta substancia como una diast3sa.

\section{NUESTRAS INVESTHGACIONES}

E1 presente trabajo se basa en el estudio clínico-experirental que publicaran Rosenthal y Lieberman en el año 1931 (28) sobbre el papel que desempeña el Lisozima en el desarrollo de la flora intestinal del recién nacido y lactante.

Ellos observaron que el tracto intestinal del recién nacido, estéril en el momento del nacimiento, es invadidio, dentro de un corto período de tiempo, por los microorganismos de1 medio ambiente. Esta flora intestinal inicial desaparece ai tercero o cuarto día en los lactantes alimentados en forma natural y es reemplazada por una flora, en la cual predomina ei Lacrobacillus bifidus. En los niños alimentaders en forma artificiall no sucede lo mismo, desarrollándose una flora microbiana intestinal muy variada y sin predominio de ninguna especie determinada.

Tratando dé investigar la causa dé la modificación. que experimenta la flota microbiana inicial en los niños ali- 
rnentades en forma natural, Rosenthal y' Lieberman fijaron isu atenciön en las deposiciones y trataron de buscar en ellas 1a existencia de algún facter capaz de destruir a los gérmenes invasores. Para ello prepararon un extracto de deposiciones y lo pusieron en contacto con una cepa de Sarcinas, germen saprófito del aire, que tiene los caracteres de coco gram positivo, se disporre en tétradas y cuyas colonias en agar placa son muy típicas y fácilmente diferenciabiles.

La técnica empleada por estcs investigadores en sus experiencias, fué la siguiente:- "el extracto se preparó mezclando deposicicnes de un lactante de una semana de edad. con cantidad suficiente de suero fisiológico, hasta formar una pasta espesa. Esta se centrifugó a una gran velocidad. por espacic de 20 minutos, y se decantó el sedimento. Como un representante de las bacterias dei aire, seleccionamos una cepa de Sarcina. que habíamos aislado del aire por exposición de placas de agar descubiertas. Se eligió este germpa, porque su aspecto típico al microscopio permite reconocerlo fácilmente. Se obtuvo una suspensión standard de Sarcinas, en $5 \mathrm{cc}$. de suero fisiológico; $0,5 \mathrm{cc}$. de esta suspensión, con $2 \mathrm{cc}$. de extracto de depcsiciones, se incubó a 45 grados. Un estudio microscópico en fresco de gotas sucesivas de esta mezcla, tcmadas a intervalos de media hora, reveló la destrucción completa y lisis de las Sarcinas en una a dos horas".

Estudiando los caracteres físico-químiccs del principio lítico revelado en las deposiciones, estos autores compruehan su nctable resistencia a los agentes físicos y químicos, demostrando que no es afectado por temperaturas de $56^{\circ}$ y que es inactivado sólo después de una hora y media a $65^{\circ}$ o después de 3 minutos a $100^{\circ}$. Su poder bacteriolítico no es alterado por el éter ni cloroformo. La filtración a través de papel filtro, cambia el principio activo del extracto probablemente por absorción.

Rosenthal y Lieberman, por todas estas razones; identifican el principio lítico encontrado por ellos en las deposiciones, con el Lisozima.

A continuación investigan la presencia de Lisqzima en las deposiciones de niños alimentados en forma natural $y$ artificial, para lo cual examinan un total de 81 muestras, concluyendo de sus investigaciones que el Lisozima se encuentra presente sólo en las deposiciones de niños alimentados al pecho, y no en los alimentados con fórmulas de lectie de vaca, de lo que deducen que tal principio se encuentra contenido en la leche humana y que atraviesa el tracto intes- 
tinal, apareciendo en las deposiciones, sin ser destruído por él jugo gástrico ni por las secreciones intestinales.

Basándonos en las experiencias de Rosenthal y Lieberman, las que hemos modificado en parte y ampliado, verificamos en la Cátedra el presente trabajo de orden experimental.

\section{MATERIAL Y TECNICA USADOS EN NUESTRAS EXPERIENCIAS}

\section{Germen de prueba.}

. Hemos utilizado la misma cepa de Sarcina test. cmpkada en todas las investigaciones efectuadas en la Cátedra, sobre el Lisozima.

Dicha. Sarcirs fué aislada del aire en 1930 por L. Rosenthal, del Liboratotio del United Israel Zion Hospital. Eila ha sido utilizada por Paul S!. Prickest, de! Laboratorio de Mead. Johnson and Compang, Evansville, Indiana, en. sus trabajos sobre I.isozima. y fué él quien nos envió dicha epa pata nurstras investigaciones.

El estudio de suś cazacterísticas morfo'ógicas, culcuralas y fisiolóxicas, ya fus realizado en la Cátedra en 1942. por lo cual no insistitemos mayormente $y$ sólo diremos que se trata de un germen de forma esférica. dispuesto an létradas, no esporvíado, inmóvil. Gram positivo. En agar estríz tiene diasiolio abundante en fotma invasor, plano. ligetamente levantado, opaco, de superficie lisa $\mathrm{y}$ húmeda, color amarillo limón. sin olor, de consistencia viscosa: no altera el medio, paede emulsionarsz fácilmente, dațdo una enu!sión homogénen. Las colonias en agar placa son pequeñas, redondeadas, de smperficie búmeda, de color amarillo cremoso.

\section{Deposiciones.}

En nuestras experiencias hemos utilizado muestras de meconió $y$ deposiciones de niños recién nacidos de la Maternidad del Hospital Baroos Luco ${ }^{*}$ de I.äctantes del Hospital Luis Calvo Mackentia. Estos úlitimos niños, en los casos en que fucron alimintados en forna nataral, tomaban leche hamana urdeñada. Es del caso hacer notar que, en su mayotía, se trataba de niños distróficos, contrariámente a los primetos, que fueron. en su totalidad, catalegados cormo clínicamiante sanos.

\section{Preparación del extracto de deposiciones.}

1. A una cantidad indetermiriada de deposiciones (recogidas genezalrente dé la primera' muda), agregamos ' $10 \mathrm{cc}$.' de suéro fisiológico, agitando hasta formar una masa semi líquita. 
2. Centrifugamos dicha mezcla a razón de 5,000 revoluciones por rinuto, por espacio de 20 minatos.

3. Decantamos el sedimento. obteniendo el sobrenadante como exteacto de deposiciones. Este extracto, asi obtanido. to mezclamos con un volntmen igual de éter sulfúrico. Hlevando en seguida esta mezcla al batiomaria a 50 grados; hasta la completa evapotación del zter, is que se conseguía después de hora $y$ midia de calentamiento. En esta forma obtuvimos el extracto de deposiciones libre dz impurez.25. ya que la esterilización con éter y el ealentamiento a 50 grados, no afectan al Lisozima qu? pudieran contener, en ranto que exclnger 1. intervención di las bacterias del grupo Mesentericus-subtilis. Aque purden cricontrarse en las deposicionsa $y$ que, tal como to ban demostrado Nicolle Rosenthal. son capaces dz producir un fermento lítico activo.

\section{Preparación de la emulsión de sarcinas.}

1. A nr caltivo de 24 horas en agat tendido de Sarcina testi agregamos $30 \mathrm{cc}$ de suero fisiológico. agitamos.

2. 0.1 cc. de esta mezclí agregamos a un tubo de agar fundido y enfrisdo a. 45 grados.

3. Vaciamos a placas de Petri, e incubamos a $77^{\circ}$ grados por espacio do 24 horas, at cabo de lás cuales lemos los tisultados obtenidos.

4. Usamos dos tubos de control: uno de ellos en el que reemplazibanos el extracto de diposiciones por suero fisiolágico. F otro en el que sólo teníamos extracto de deposiciones. Este último to usábamos con el fin is tener lá sequridad de que mediante la esterifización previa habiamos desinuído la flora microbiana intestinal normal.

En esta forma, investigábamos el podet litico inhrbidar del extracto de deposiciones. frente a la Sarcina t'zet. en forma instantánea.

\section{Interpretación de los resuliados.}

A fin de facilitar la lectura de los resultados obtenidos in todas nuestras experiencias, hemos adoptado la siguiente pauta para su interpretación:

\footnotetext{
++++ Lisis total, no hay dexarrollo microbiano.

+++ Hay disminación en un $75 \%$ en el número de colonìs, compararivamente a la placa control.

++ La reducción det numero de colonias alcanza a un $50 \%$ con respecto al control.

+ Hay disminación del número de colonias en un $25 \%$.

- El múmero de colonizs es sensiblemente igual al de la plaxa contral,
} 


\section{PROTOCOLO DE NUESTRAS INVESTIGACIONES}

\section{Primera serie de experiencias.}

Efretuamos la investigación del Lisozima en el meconio $y$ d-posicicunes de los recién naxidos alimentados con luche materna.

Estudio verificado en 75 nifios. protocolizados en la Maternidad del-Hospital Barros Laco, $y$ cuyas edadss fluctuaban entre 1 día y 12 días.

Los resultados obtenidos los rssumimos en al cuadro siguiente:

\section{.CUADRO N.: 1.}

Investigación del poder lítrco-iniabidor del meconio $y$ deposiciones de los recién nacidos alimentados con lechs marterna. frente a ta Sarcina test. Acción instantánea.

\begin{tabular}{|c|c|c|c|c|c|c|c|c|c|}
\hline \multicolumn{3}{|c|}{ Protocolo } & Nombre & \multicolumn{2}{|c|}{ Ėdad } & \multirow{2}{*}{$\begin{array}{l}\text { Proced, } \\
\text { I. HBI... }\end{array}$} & \multirow{2}{*}{$\frac{\mathrm{Ob}^{\mathrm{N}}{ }^{\mathrm{g}}}{56897}$} & Alimentación & Lisorzina \\
\hline 99.44 & ". & ... & P. $\mathrm{M}$. & 1 & d. & & & 0 & 0 \\
\hline 11469 & .. . & : .. & T. $S$. & 1 & ". & " & 60347 & 0 & 0 \\
\hline 9938 & $\because$. & $\cdot \cdot \cdot$ & A. $S$. & $\cdot 1$ & $"$ & " & 60315 & 0 & 0 \\
\hline 11470 & .. . & $\because \cdot$ & R. A. & .1 & "- & $"$ & 60311 & 0 & 0 \\
\hline 11471 & .. .. & $\cdots$ & A. 0 . & 1 & " & * & 60167 & 0 & 0 \\
\hline 9946 & .. .. & .. & E. S. & 2 & $"$ & $"$ & 59936 & 0 & 0 \\
\hline 99.61 & .. .. & $\cdot \cdots$ & R. P. & 2 & $"$ & $"$ & 32837 & 0 & 0 \\
\hline 9939 & .. .. &.+ & o. C. & 2 & $m$ & $"$ & 60246 & 0 & 0 \\
\hline 11476 & .. . . & . .. & M. P. & 2 & $"$ & " & 59951 & 0 & 0 \\
\hline 1472 & .. .. & $\cdots$ & T. R. & 2 & ". & $"$ & 51730 & 0 & 0 \\
\hline 11464 & .. .. & . & C. P. & 3 & $"$ & " & 60245 & L. Materna & + \\
\hline 11465 & .. ... & . .. & E. F. & 3 & $"$ & $"$ & 59492 & $\because$ & \\
\hline $11 \div 66$ & .. ... & : .. & G., s. & 3 & .. & " & 59890 & ". & \\
\hline 11467 & .. & . & M. P. & 3 & ${ }^{+*}$ & $"$ & 31042 & "r & \\
\hline 11474 & .. & . .. & R. M. & 3 & " & $"$ & 59758 & El 5 r/s & \\
\hline 11432 & .. & - .. & L. C. & 4 & $"$ & "t & 56187 & I. Materna. & + \\
\hline 11438 &.. & •.. & H. S. & 4 & $"$ & $"$ & 59770 & ." & \\
\hline 11441 & $\because:$. & $\therefore$ & T. B. & 4 & " & •" & 5978 & " & \\
\hline 11475 & .... & . .. & D. B. & 4 & $"$ & $"$ & 135 & $\because *$ & \\
\hline 11433 & .. .. & . .. & L. P. & 4 & $" ”$ & " & 6045 & " & ++ \\
\hline 11424 & .. & $\cdots$ & E. C. & 4 & $"$ & 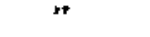 & 723 & $"$ & + \\
\hline 11435 & .. .. & . .. & Y. S. & 4 & “* & $"$ & 600 & "• & ++ \\
\hline 11477 & .. ... & . .. & V. V. & 5 & $\ddot{ }$ & $"$ & 5 & " & $\vdash-$ \\
\hline 11478 & $\cdots \cdot$. & . .. & E. H. & 5 & $"$ & " & 60 & $"$ & +- \\
\hline 11479 & .... & $\cdot$. & G. Y. & 5 & $"$ & “ & 44480 & $"$ & $+++t$ \\
\hline 11480 & .. ... & ... & C. $\mathbf{M}$. & 5 & $"$ & $"$ & $20 ? 18$ & $\because$ & ++++ \\
\hline $994 \mathrm{t}$ & ... & ... & M. A. & 5 & $"$ & $"$ & 45281 & $+"$ & ++++ \\
\hline 9965 & .. .. & $\therefore .$. & E. 5 . & 5 & $"$ & " & Pann & $"$ & ++++ \\
\hline 12137 & $\ldots .$. & $\cdot \cdot \cdot$ & B. E. & 5 & $"$ & $"$ & 41152 & $"$ & $++t+$ \\
\hline 12138 & ... & $\cdot \cdot$ & A. C. & 5 & $"$ & " & 59977 & " & $+++t$ \\
\hline 12139 & .. . & $\therefore$ & E. $s$. & 5 & 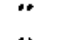 & $"$ & 60109 & " & ++++ \\
\hline 12140 & .. .. & .. & E. $s$ & 5 & $"$ & $\therefore$ & 49851 & " & ++++ \\
\hline 11.430 &.... & . .. & A. P. & 6 & $\bullet$ & $"$ & 60325 & " & $+t+t$ \\
\hline $11+31$ & .. .. & $\cdot \cdot$ & M. S. & 6 & " & " & 28309 & $"$ & \\
\hline
\end{tabular}




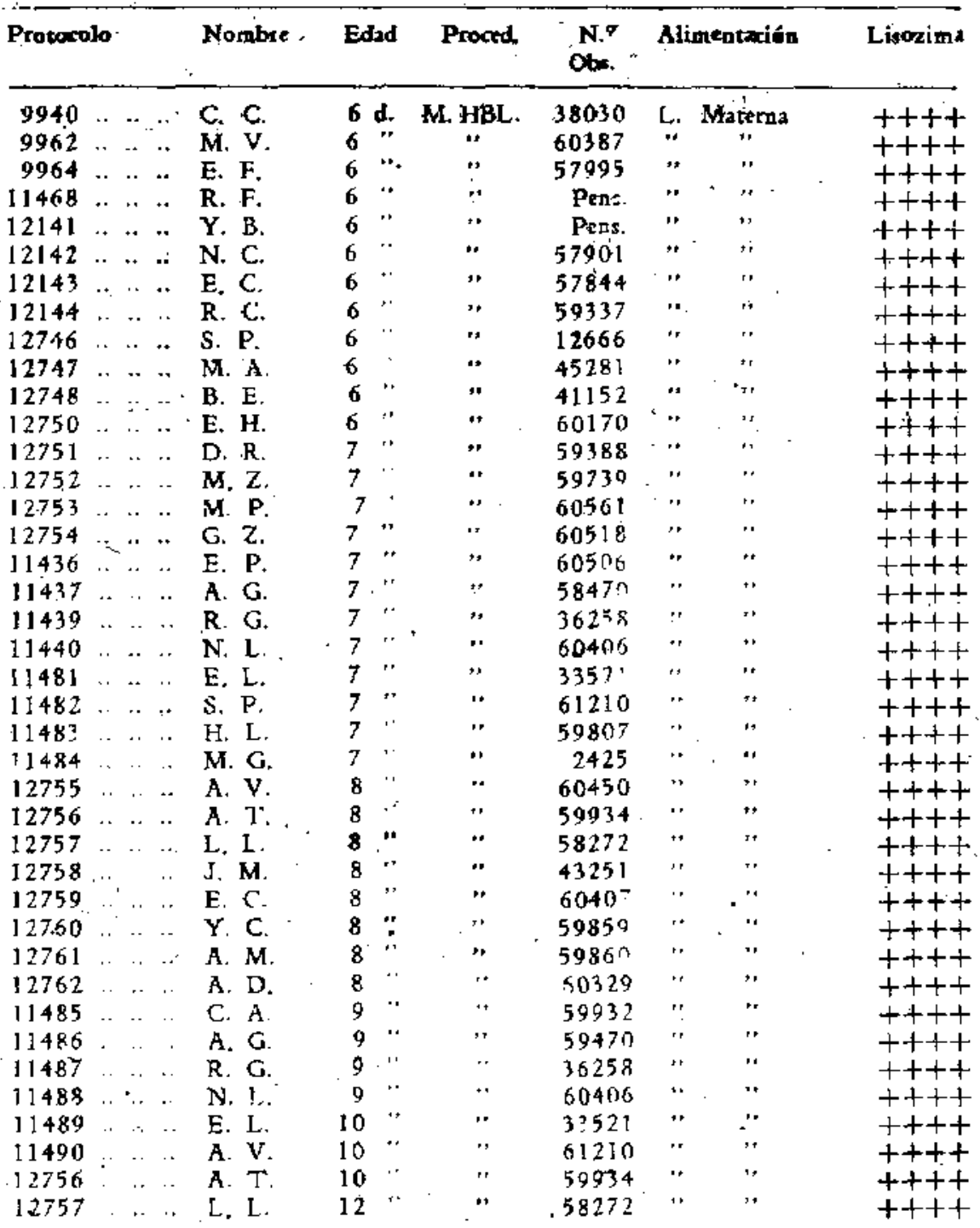

Conchusicnes de la primera sis ie de expariencias.

$1 .^{9}$ Demuéstrase en la totalidad de los casos investigados que el meconio carece de Lisozima.

2.9 Las deposiciones de recién nacidos alimentados con leche materna demostraron, en todos los casos analizados, un gran contenido lisozímico. 
3.9 La aparición de Lisozima en las deposiciones coin-1 cidió constantemente con 1a iniciación del amamantamiento.

4." Los controles verificados en forma continuada, a partir del 1.er día del amamantamiento hasta el $12 .^{\circ}$ día, demostraron un contenido lisozímico constante.

\section{Segunda serie de experiencias.}

Se investigó el poder inhibidor lítico da laz deposiciones de 79 lastantes. cuyas edides fluctuaban' entre 15 días y 22 meses, alimentados en forma nu. tural (lecthe homana ordeñada), mixta y anificial.

Estos casos. fueron protocolizados en el Hospital Luiz Calvo Mackenna.

- Los resultados obtenidos están risumidos en el cuadmo sigujente:

\section{CUADRO N" 2}

Investigación del podar inhibidot litico de las deposiciones de lactares, frente a גa Sarcina test. Acción instantánea.

\begin{tabular}{|c|c|c|c|c|c|c|c|c|}
\hline Prof̧ocolo & Nombere & \multicolumn{2}{|c|}{ Edad } & \multirow{2}{*}{$\begin{array}{l}\text { Proced. } \\
\text { H. LCM. }\end{array}$} & \multirow{2}{*}{$\frac{N{ }^{\circ} \text { Obs. }}{43 / 682}$} & \multicolumn{2}{|l|}{ A.tumentación } & Lisozima \\
\hline 9928 & P. B. & 15 & ds. & & & 1. $\mathrm{H}$, & & $t$ \\
\hline 9920 & J. 0 & 18 & & & $42 / 623$ & & & \\
\hline $9348 \ldots .$. & O. T. & 21 & & $r$ & $43 / 360$ & L.H. $-\mathrm{EI}$ & & \\
\hline $9350 \ldots$. & M. T. & & $\mathrm{ms}$ & ". & $43 / 466$ & L.H.J. de F. & & \\
\hline $9351 \ldots$. & G. S. & 1 & 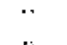 & . & $43 / 280$ & " & & \\
\hline $9919 \ldots$. & B. C. & & " & $"$ & $43 / 624$ & L. M. & & \\
\hline $9929 \ldots .$. & N. N. & 1 & " & $\therefore$ & $43 / 688$ & L.H.-E 1 & & \\
\hline $9930 \ldots$ & $\mathrm{J}: \mathrm{C}$ & 1 & $"$ & $"$ & $43: 655$ & I. M. & & \\
\hline $31419 \ldots$ & C. A. & 1 & ". & Part. & - & $"$. & & \\
\hline $11428 \ldots .$. & L. G. & 1 & 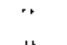 & H. I_CM. & $43 / 670$ & L.H. -E I & & \\
\hline $11429 \ldots \ldots$ & L. N. & ; & 14 & $\cdot$ & 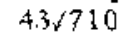 & , & & $++t$ \\
\hline $9.349 \quad . . \therefore$ & L. V. & 2 & $2 "$ & $"$ & $43 / 213$ & $"$ & & -+ \\
\hline $9459 \ldots$ & 0.0 & 2 & $"$ & $"$. & $43 / 622$ & L. $\mathrm{H}$. & & ++ \\
\hline 9460 & M. O. & 2 & $2^{-1}$ & $\because$ & $43 / 621$ & & & $+t+t$ \\
\hline $9918 \ldots \ldots$ & B. S. & 2 & $2 "$ & $"$ & $43 / 259$ & - $\mathrm{L} 2 / 38 \% \mathrm{c}-\mathrm{L} . \mathrm{H}$. & & $+1+1$ \\
\hline $9931 \ldots$ & C. N. & 2 & " & " & $43 / 303$ & $\mathrm{~L} 2 / 3 \mathrm{~B} / \mathrm{K}-\mathrm{LH}-\mathrm{LA}$ & & $+t+t$ \\
\hline $11410 \ldots \ldots$ & N. C. & 2 & $"$ & $"$ & $43 / 256$ & L:H-Fl-J. dz F. & & +++ \\
\hline $11426 \ldots$ & C. N. & 2 & 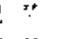 & $"$ & $43 / 620$ & I. $\mathrm{H}$. & & $++t+$ \\
\hline $11427 \ldots \ldots$ & E. P. & 2 & " & " & $43 / 640$ & L2/38\%-LH-LA & & $t+t$ \\
\hline $11430 \ldots$ & O. U. & 2 & " & $"$ & $47 / 504$ & L.. H. & & $+t+t$ \\
\hline $11431 \ldots$ & C. H. & 2 & 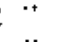 & Part: & - & $"$ & & $+t+t$ \\
\hline $9354 \ldots \ldots$ & M. B. & 3 & " & H. LC.M. & & Attificial & & 一 \\
\hline 9355. & M. M. & 3 & $3 \cdot$ & $\because "$ & & & & - \\
\hline $9924 \ldots \ldots$ & H. $\mathrm{O}$. & 3 & " & ", & $43 / 302$ & L.H. -L.A. A. & & $+t+t$ \\
\hline $9932 \ldots$ & E. N. & 3 & 3 & " & $43 / 319$ & $\mathrm{~L} 2 / 3 \$ \% / \mathrm{LH}-\mathrm{LA}$ & - & +++ \\
\hline $11415 \ldots$ & R. F. & 3 & 3 & Prrt. & 一 & L. ,M. & & ++++ \\
\hline $11416 .$. & $\mathrm{N} \cdot \mathrm{C}$. & 3 & " & & & "y & & $++t+$ \\
\hline $11417 \ldots$ & C. C. & 3 & " & 18 & 3 & 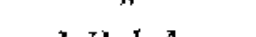 & & ++++ \\
\hline $\begin{array}{l}11421 \ldots \\
11422\end{array}$ & V. V. & 3 & " & H. LCM. & $\begin{array}{l}43 / 562 \\
43 / 520\end{array}$ & L.H.-L.A. & & $++t$ \\
\hline & E. & 3 & & & & & & \\
\hline
\end{tabular}




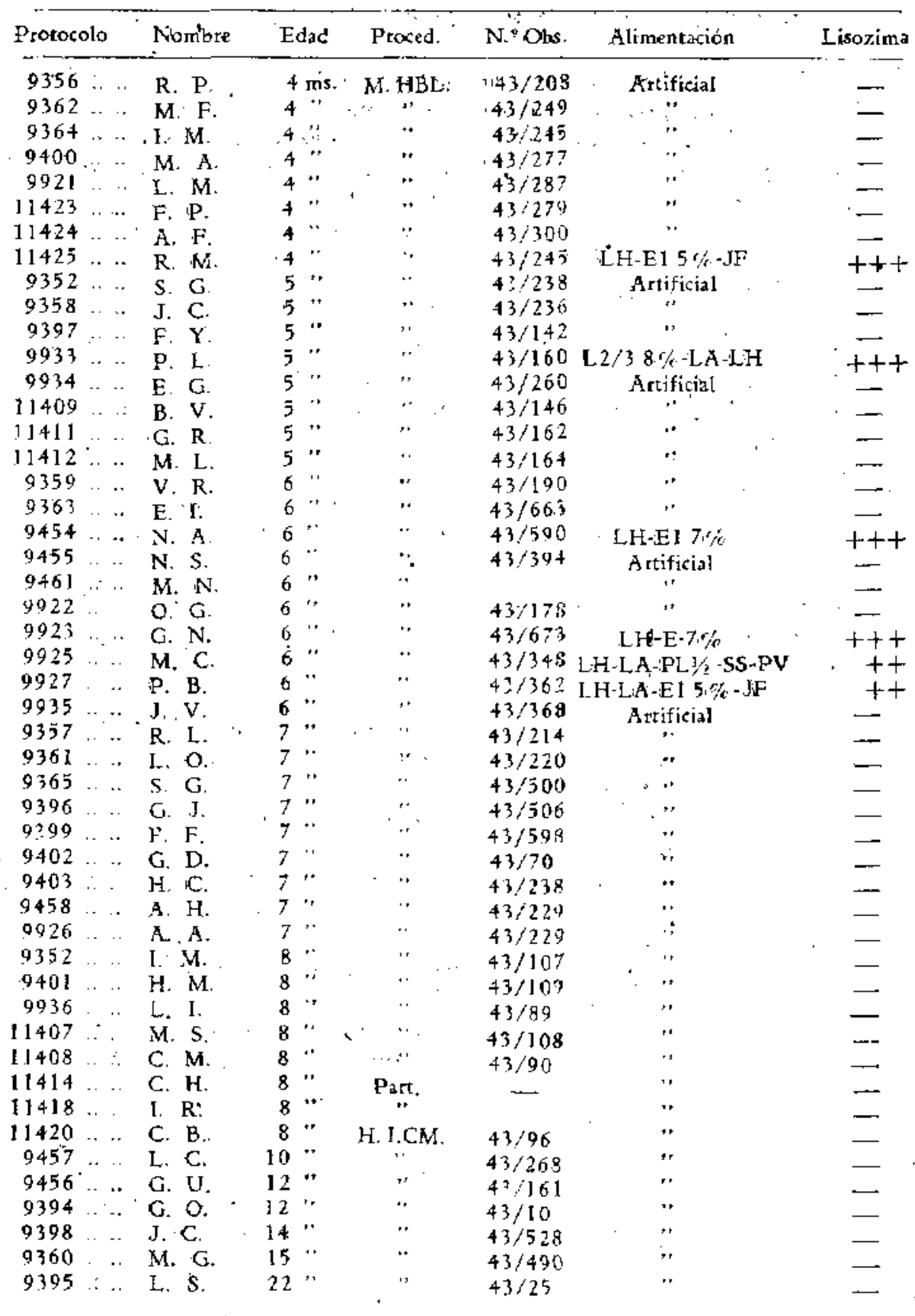


Conclustones de la segunda serie de experiencias.

1. Las deposiciones de lactantes alimentados con leche humana ordeñada, contienen Lisozima.

2. El contenido lisozímico que poseen las deposiciones de estos niños, es tan elevado como el de los niños alimentades con leche materna.

3. La actividad lisozímica fué siempre constante $e$ independiente de la edad del lactante.

4. Los lactantes alimentados en forma mixta, demostraron contener Lisozima en sus deposiciones.

5. Las deposiciones de estcs niños presentaron un contenido lisczímico inferior al de los niños alimentados en forma natural, variando su concentración en forma proporcionalmente directa a la cantidad de leche humana que recibian.

6. Los lactantes que recibian alimentación artificial no presentaton, en ningún caso, Lisozima en sus deposiciones.

ACCION DEL LJSOZIMA CONTENIDO EN LAS DEPOOSICIONES

DE RECIEN NACIDOS, FRENTE A ALGUNAS ESPECIES MIOROBIANAS SAPROFITAS Y PATOGENAS

Hemos creído de interés investigar la acción del Lisozima fecal de los recién nacidos, frente a algunos gérménes patógenos del tracto digestivo.

Procedimos a estas investigaciones después de haber comprobado. utilizando la Sarcina test como especie microbiana sensible, el alto poder lisozímico de las deposiciones a examinar.

Verificamis este estudio en 52 muestras de deposiciones cbtenidas de recién nacidos, cuyas edades fluctuaban entre 4 y 8 dias.

Emp'eamos las siguientes especies microbianas: Escberichia coli, Eberthella typhosa, Salmonella paratyphi A.; Streptococcus faecalis (enterococo). Proteds morganii. Shigella paradysenteriae (Bacilo Flexner).

En cuanto a la técnica seguida, ella ha sido análcga a la ya descrita para las experiencias con Sarcina test.

Hemos variado la dilución déi extracto de deposiciores desde $1 / 10$, que corresponde a la dilución empleada en las experiencias verificadas con la Sarcina test, hasta $1 / 200$. 
Así mismo, hemos variado el tiempo de cantacto entre la emulsión microbiana y el extracto de deposiciones, desde las 24 horas hasta la auración de la acción instantánea, que en las experiencias con Satcina test fué el tiempo óptimo de acción.

Los protocolos de las experiencias y los resultados obtenidos, frente a cada una de estas especies microbianas, están resumidos en la serie de cuadros siguientes:

\section{CUADRO N.: 3}

Acción del Lisozima contenido en las deposicioness del racién nacido sobie 1a Escherichia coli.

\begin{tabular}{|c|c|c|c|c|c|c|c|c|c|c|}
\hline \multirow{2}{*}{$\begin{array}{l}\text { Meetra } \\
\text { N. }\end{array}$} & \multicolumn{3}{|c|}{ Extr. Deposic. } & \multicolumn{4}{|c|}{$\begin{array}{r}\text { Tiempo de contacto } \\
\text { de } 106\end{array}$} & $\begin{array}{l}\text { en toras e } \\
\text { resaltados. }\end{array}$ & \multicolumn{2}{|c|}{ interpretación } \\
\hline & & & & & nstant. & 3 & 6 & 12 & 18 & 2 \\
\hline \multirow[t]{4}{*}{1.2137} & & & & & & & & & & \\
\hline & & .. & .. $\quad .$. & .. & - & 1 & 一 & 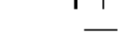 & & \\
\hline & & & .. .. & .. & - & - & - & - & & \\
\hline & & . & $\therefore \quad .$. & .. & - & -- & 一 & - & 一 & \\
\hline \multirow[t]{4}{*}{2138} & &. &.$\cdot \cdot$ & & ++ & + & $\begin{array}{l}++ \\
++\end{array}$ & & & \\
\hline & & 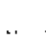 & & .. & \pm & - & + \pm & - & $t$ & \\
\hline & & .. &... & . & - & - & 一 & - & - & \\
\hline & & . : & .. & & - & - & 一 & - & - & \\
\hline \multirow[t]{4}{*}{139} & & .. & $\begin{array}{ll}. . \cdot \\
. & . .\end{array}$ & & $\begin{array}{r}++ \\
+\end{array}$ & + & & + & $\begin{array}{l}+t \\
+t\end{array}$ & \\
\hline & & & .. .. & & - & - & & & & \\
\hline & & & .. $\quad .$. & & - & - & 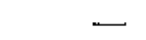 & - & 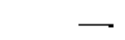 & \\
\hline & & . & .. $\quad .$. & & - & - & $\rightarrow$ & - & & \\
\hline \multirow[t]{5}{*}{2140} & & 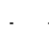 & .. .. & & ++ & tr & $+t$ & + & + & \\
\hline & & . &... & & + & + & $+t$ & & + & 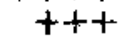 \\
\hline & & ". & .. .. & .. & - & - & - & & & \\
\hline & & .. & & .. & - & - & - & - & - & \\
\hline & & & .. & & - & 一 & - & & & \\
\hline \multirow[t]{4}{*}{2141} & &.. & .. .. & & ++ & $++t$ & $++t+$ & + & -++ & 4 \\
\hline & & . & $\cdots .$. & & + & + & ++ & ++ & ++ & \\
\hline & & “. & .". & : & $=$ & E & 工 & - & I & \\
\hline & & .. & ... & & - & 一 & - & - & 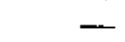 & \\
\hline \multirow[t]{4}{*}{142} & &.. & 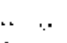 & & ++ & & ++++ & $1++$ & ++ & \\
\hline & & & & & + & & $+t$ & ++ & ++ & \\
\hline & &.. & $\begin{array}{ll}\cdots \\
\cdots\end{array}$ & & - & - & - & - & & \\
\hline & & $\therefore$ & $\therefore$ & & - & - & - & - & & \\
\hline & & & & & & & $+4+t$ & $+t+t$ & & \\
\hline
\end{tabular}




\begin{tabular}{|c|c|c|c|c|c|c|c|c|c|c|}
\hline \multirow{2}{*}{$\begin{array}{l}\text { Muestra } \\
-\frac{-}{} \\
N^{\prime}\end{array}$} & \multicolumn{4}{|c|}{ Extc, Deposic. } & \multicolumn{6}{|c|}{$\begin{array}{c}\text { Tiempo de sontacto en horas e interpretación } \\
\text { de los resoltados. }\end{array}$} \\
\hline & & & & & Instant. & 3 & 6 & 12 & 18 & 24 \\
\hline & $1 / 20$ & . & & .. & + & + & $+t$ & ++ & $t+$ & $+t$ \\
\hline & $1 /$ &.. &.$\cdot$ & .. & -- & $-\dot{ }$ & - & - & $\longrightarrow$ & 一 \\
\hline & $1 /$ & . & .. & & - & - & - & 一 & - & -- \\
\hline & $1 /$ & .. &. & .. & - & - & - & 一 & - & 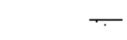 \\
\hline \multirow[t]{5}{*}{12144} & 1 & .. & .. &.. &.++ & & ++ & $++t+$ & $+t$ & ++++ \\
\hline & &.. & .. & $\cdots$ & + & + & ++ & ++ & 1 & +1 \\
\hline & 1 & .. & & .. & - & $\tau$ & - & - & 一 & - \\
\hline & 1 & .. & . & .. & 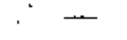 & - . & - & - & - & - \\
\hline & 1 &.. &.. & & - & - & - & - & - 一 & 一 \\
\hline \multirow[t]{5}{*}{12145} & $1 /$ & & &.. &..+ & $++t$ & ++ & $+++t$ & ++++ & ++++ \\
\hline & 1 & & & .. & + & $t$ & $+t$ & $t+$ & & \\
\hline & 1 & .. & & .. & $\rightarrow$ & 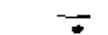 & - & - & - & 一 \\
\hline & 1 & & .. & .. & $\cdots$ & - & - & - & - & - \\
\hline & 1 & &.. &.. & - & $-m$ & - & - & - & - \\
\hline \multirow[t]{5}{*}{12146} & $1 /$ & .. & .. & $\therefore$ & $\therefore+t$ & +++ & $+t+t$ & $++t+$ & $+++t$ & $+++\dot{1}$ \\
\hline & 1 & .. & $\cdot \cdot$ & .. & + & + & + & ++ & ++ & $1+$ \\
\hline & 11 & . & $\cdot \cdot$ & & $\longrightarrow$ & $\bar{x}$ & - & - & - & 一 \\
\hline & 1 & & $\therefore$ &.$\cdot$ & - & - & - & - & - & $\tau$ \\
\hline & 1 & 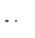 & .. &.. & - & - & - & 一 & - & - \\
\hline \multirow[t]{5}{*}{12147} & $1 / 10$ & .. &. &.. & $\cdots+-4$ & +++ & $+t+t$ & $+++t$ & ++++ & $++t+$ \\
\hline & $1 /$ & .. & .. &. & + & + & $+t$ & ++ & $+t$ & \\
\hline & $1 /$ & & .. &. & - & - & - & - & - & - \\
\hline & $1 \%$ & .. &.. &.. & - & - & بي- & $\cdots$ & - & - \\
\hline & $1 /$ & $\because$ & .. &.. & - & $\rightarrow$ & - & - & - & 一 \\
\hline \multirow[t]{5}{*}{121.48} & 1 &.. &.. & .. &..++ & $++t$ & $+\frac{1}{3}+t$ & $+t+t$ & $++t+$ & ++++ \\
\hline & $1 /$ & & . & .. & + & + & ++ & ++ & $+t$ & +++ \\
\hline & & $\because$ &.. & & - & - & -- & - & - & -- \\
\hline & $1 / 1$ & 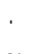 & &. & - & - & - & - & - & - \\
\hline & $1 / 2$ & & & & .. - & & - & & & \\
\hline
\end{tabular}

\section{Conchusiones.}

De esta serie de experiencias, pueden deducirse las siguientes conclusiones:

1. Las deposiciones de recién nacidos, contienen Lisozima activo para lia Excherichia coli.

2. El grado de actividad es directamente proporcional a la concentración y al tiempo de contacto.

3. Al $1 / 10$ se produce lisis parcial en forma instantánea, la que se hace total de'spués de 6 horas de contacto.

4. Al $1 / 20$ la lisis es apenas perceptible hasta las 3 horas; se va haciendo más evidente a medida que aumenta el tiempo de contacto, sin llegar en ningún caso a la pioduc crón de lisis total. 
5. Al $1 / 50$ hubo ligera acción después de 24 horas de contacto, en dos del total de las muestras examinadas:

6. Al $1 / 200$, el extracto de deposiciones no ejerce ninguna acción frente a la Eschericbia coli.

\section{CUADRO $\mathrm{N}: 4$}

Arción del Lisozima contenido en las deposiciones del recién racido. sobre la Eberthella typhosa.

\begin{tabular}{|c|c|c|c|c|c|c|c|c|c|c|c|}
\hline \multirow{2}{*}{$\begin{array}{l}\text { Mnestra } \\
\text { N. }{ }^{*}\end{array}$} & \multirow[t]{2}{*}{ Extr } & \multirow{2}{*}{\multicolumn{3}{|c|}{ Deposic. }} & \multicolumn{7}{|c|}{$\begin{array}{c}\text { Tiempo de contacto en botas e interpretación } \\
\text { i de los resultacis: }\end{array}$} \\
\hline & & & & & & Istant, & 3 & 6 & 12 & 18 & 24 \\
\hline \multirow[t]{5}{*}{12137} & 1410 & .. & .. & $\because$ & .. & - & + & + & & & \\
\hline & & .. &.. & $\therefore$ &.. & - & - & - & - & + & +1 \\
\hline & $1 /$ & .. & .. & $\cdot \cdot$ &.. & - & - & $\cdot--$ & - & - & - \\
\hline & $1 /$ & .. & .. & .. & $"$. & - & 一 & - & - & - & - \\
\hline & $1 /$ & + & .. & &.. & - & 一 & $\longrightarrow$ & - & $\longrightarrow$ & - \\
\hline \multirow[t]{5}{*}{12138} & $1 / 10$ & .. & .. & $\because$ & $\cdot \cdot$ & $\longrightarrow$ & + & + & ++ & -+ & \\
\hline & .17 & .. & .. & $\therefore$ & $\cdot \cdot$ & - & - & - & - & + & rt \\
\hline & 1 & . &.. & $\because$ & .. & -- & - & $\longrightarrow$ & 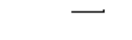 & - & - \\
\hline & 1 & .. & .. & $\cdot \cdot$ & .. & - & - & - & - & - & - \\
\hline & & .* & .. & $\cdots$ &.. & - & $\cdots$ & - & - & 一 & - \\
\hline \multirow[t]{2}{*}{12139} & If & .. & &.. & 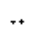 & $\cdot-$ & + & + & ++ & ++ & ++++ \\
\hline & $1 /$ & .. & .. &.$\cdot$ &.. & - & - & - & + & + & +4 \\
\hline \multirow[t]{3}{*}{ - } & 1) & & .. &.. & .. & - & - & 一 & - & - & - \\
\hline & 1) & & .. & .. & & - & - & $\cdots$ & 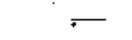 & - & - \\
\hline & $1 /$ & .. & .. &.. & . & - & - & 一 & - & - & - \\
\hline \multirow[t]{5}{*}{12140} & $1 / 1$ & . & .. & .. &.. & 一 & + & + & ++ & +++ & ++++ \\
\hline & I & & .. & .. &.. & 一 & - & - & $\div$ & + & \pm \\
\hline & 1) & & .. & $\therefore$ & .. & - & - & - & - & $\longleftarrow$ & - \\
\hline & 17 & & .. & .. &.. & - & - & $\dot{-}$ & - & - & $m$ \\
\hline & $1 / 2$ & .. & .. & .. &.$\cdot$ & - & - & $\longrightarrow$ & 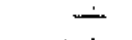 & $\longrightarrow$ & - \\
\hline \multirow[t]{2}{*}{12141} & $1 / 1$ & .. & .. & $\cdot$. & $\cdot \cdot$ & $\longrightarrow$ & + & + & +1 & $4+$ & ++++ \\
\hline & $1 / 2$ & & . & $\cdot$. & . & - & 一 & - & + & + & ++ \\
\hline & $1 / 5$ & " & .. & .. & .. & - & - & - & - & - & $\longrightarrow$ \\
\hline & $1 / 1$ & ." & .. & & $\cdot$. & - & - & 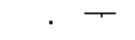 & - & . & $m$ \\
\hline & $1 / 200$ & .. & $\cdot$. & $\cdot \cdot$ & $\therefore$ & - & - & - & 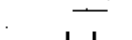 & - & - \\
\hline \multirow{4}{*}{12142} & $1 / 10$ & . &.. & $\begin{array}{l}. . \\
. .\end{array}$ &. & 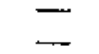 & \pm & \pm & $\begin{array}{r}++ \\
+\end{array}$ & +++ & ++++ \\
\hline & & . & $\cdots$ & .. & .. & - & - & . - & + & + & ++ \\
\hline & 1 & . & $\ldots$ & . & . & - & $\ldots$ & - & ? & 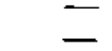 & - \\
\hline & I. & .. & $\therefore$ & . . & & $\cdots$ & $\longrightarrow$ & - & - & - & - \\
\hline \multirow[t]{5}{*}{12143} & 1) & .. & . &.$\cdot$ & & $\omega$ & + & $1+$ & ++ & +++ & +++ \\
\hline & & .. & & .. & .. & - & 一 & $\cdot-$ & 4 & + & $+t$ \\
\hline & & &.. & .. & .. & - & 一 & $=$ & - & - & - \\
\hline & & & $\therefore$ & * & & 一 & 一 & - & 一 & - & - \\
\hline & 200 & * & .. & $\cdot \cdot$ & $\because$ & - & & - & - & - & \\
\hline
\end{tabular}




\begin{tabular}{lllllllll} 
Muastra Extr. Deposic. & \multicolumn{3}{c}{ Tiempo de contacte en horas e interpretación } \\
de los tesultados
\end{tabular}

Conclusiones,

De esta serie de experimentos se deducen las siguientes conclusiones:

1. El Lisozima contenido en las depcsiciones del recién nacido, tiene acción inhibidor lítica evidente sobre ia Eberthella typhosa.

2. El grado de actividad es directamente proporcional a la concentración y al tiempo de contacto.

3. A1 $1 / 10$ se produce lisis parcial a las 3 horas, la que se hace total a las 24 horas de contacto.

4. Al $1 / 20$, su acción empieza a ejercerse a las 12 horas de contacto y no llega a ser completa aún después de 24 horas.

5. A mayores dilaciones, el extracto de deposiciones no demostró ningún efecto sobre la Eberthella typhosa, aun después de 24 horas de contactio. 


\section{CUADRO N: 5}

Acción del Lisozima fontenido en las deposiciones del recrín nacido sobce la Salmonella paratyphi $\mathbf{A}$.

\begin{tabular}{|c|c|c|c|c|c|c|c|c|c|c|c|}
\hline \multirow{2}{*}{$\begin{array}{c}\text { Muestra } \\
\ddots \\
\text { N. }{ }^{9}\end{array}$} & \multicolumn{4}{|c|}{ Extr, Deposic. } & \multicolumn{7}{|c|}{$\begin{array}{c}\text { Tiempo de contacto en borks e interpretación } \\
\text { de los resultados }\end{array}$} \\
\hline & & & & & & Instapt. & 3 & 6 & 12 & 18 & 24 \\
\hline \multirow[t]{4}{*}{12746} & $1 / 10$ & .. & & .. & .. & - & + & & 5 & & \\
\hline & 0 & .. & .. & $\because$. & .. & - & - & + & - & & $1+$ \\
\hline & $!$ & *. & .. & *. &. & $\longrightarrow$ & $\cdots$ & - & - & $m$ & 一 \\
\hline & 00 & .. & .. & $*$ & .. & - & - & 一 & - & - & 一 \\
\hline \multirow[t]{5}{*}{12747} & $1 / 10$ & .. & 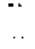 & $\begin{array}{l}. . \\
. .\end{array}$ & 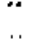 & $\overrightarrow{++}$ & + & $+\overrightarrow{+}$ & $-t+1$ & + & $t+$ \\
\hline & 1) & .. & .. &. & 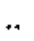 & 二 & - & + & + & + & + \\
\hline & $1 / 50$ & .. & .. & .. & .. & - & $\rightarrow$ & $\ldots$ & - & - & - \\
\hline & $1 / 100$ & .. &.. & .. & .. & - & - & 一 & 一 & - & - \\
\hline & $1 / 200$ & .. & .. & .. & .. & $\rightarrow$ & - & 一 & 一 & - & - \\
\hline \multirow{5}{*}{$\begin{array}{c}2748 \\
.\end{array}$} & $1 / 10$ & $\cdots$ & .. & $\because$ & .. & - & ++ & ++ & ++ & ++ & ++++ \\
\hline & $1 / 20$ & ., &.$\cdot$ &.. & .. & - & + & + & - & ++ & $7+$ \\
\hline & $1 / 50$ & .. & .. & .. & .. & - & - & - & 一 & $\ldots$ & 一 \\
\hline & $1 / 100$ & .. & .. & .. & $\therefore$ & - & $一$ & - & $一$ & - & $\cdots$ \\
\hline & $1 / 200$ & .. & .. & .. & .. & 一 & 一 & - & 一 & - & - \\
\hline \multirow[t]{5}{*}{12749} & $1 / 10$ & $\cdot$ & .. & .. & .. & + & & $r+$ & $5+$ & + & $+t$ \\
\hline & $1 / 2$ & .. & .. & .. & $\cdot \cdot$ & -4 & $\longrightarrow$ & + & + & + & ++ \\
\hline & $1 /$ & .. & ." & .. & ** & $\leftarrow$ & - & - & - & - & - \\
\hline & 1 & . & .. & ." & .. & - & 一 & 一 & 一 & - & - \\
\hline & 1) & .. & .. & .. & .. & - & 一 & - & 一 & - & $-\cdots$ \\
\hline \multirow[t]{5}{*}{12750} & 1) & .. & .. & .. &.. & ++ & $+t+$ & $+t+t$ & ++++ & $+++t$ & ++++ \\
\hline & $1 /$ & .. &.$\cdot$ & .. & .. & + & + & + & + & ++ & ++ \\
\hline & 1 & .. & .. & .. & .. & - & - & - & 一 & - & - \\
\hline & 1) & .. & .. & .. & .. & - & - & - & - & - & - \\
\hline & l) & .. & .. & .* & .. & - & - & - & - & - & - \\
\hline \multirow[t]{5}{*}{12751} & 3 & $\cdot \cdot$ & . & . & $\because$ & + & $+t+$ & $+t+t$ & $++t+$ & $+t+t$ & $+t+t$ \\
\hline & $1 /$ & .. & .. & .. & - & - & - & + & - & ++ & $+t$ \\
\hline & $1 /$ & .. & .. & .. & .. & $一$ & - & 一 & 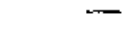 & 一 & - \\
\hline & 1 & .. & .. & .. & .. & $r$ & - & - & - & - & - \\
\hline & 1 & $\because$ & & .. & .. & $\overline{1}$ & - & - & - & - & $\longrightarrow$ \\
\hline \multirow[t]{4}{*}{12752} & $1 / 10$ & $\ddot{v}$ & 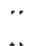 &.$\cdot$ & 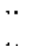 & ++ & & + & + & + & $++4+$ \\
\hline & & $\ddot{*}$ & .. &.. & $"$ & - & + & + & + & ++ & $+t$ \\
\hline & & $\begin{array}{l}. . \\
. .\end{array}$ & .. & .. & ... & - & - & - & - & - & - \\
\hline & & .. & $\therefore$ & .. & .. & - & - & - & 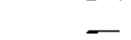 & $\rightarrow$ & \\
\hline \multirow[t]{5}{*}{12753} & $1 / 10$ & .. & .. & .. & .. & + & $++t$ & $+++t$ & $+++\dot{-}$ & & \\
\hline & $1 / 20^{\circ}$ & .. & .. & .. & .. & - & - & + & + & + & \\
\hline & $1 / 50$ & .. & .. & .. & .. & $一$ & - & - & . & - & - \\
\hline & $? / 100$ & .. & .. & .. & $\therefore$ & - & - & - & - & - & - \\
\hline & $1 / 200$ & .. & .. & .. & .. & $\ldots$ & $\leftarrow$ & - & - & $\ldots$ & -. \\
\hline \multirow[t]{5}{*}{12754} & $1 / 10$ & .. & . & .. & .. & + & +++ & ++++ & $+++t$ & ++++ & $+t+t$ \\
\hline & $1 / 20$ & .. & 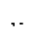 & . & .. & - & $\longrightarrow$ & + & + & + & $+\div$ \\
\hline & $1 / 50$ & .. & .. & .. &.. & - & 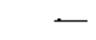 & - & - & - & - . \\
\hline & $1 / 100$ & .. & & .. & .. & - & - & -- & - & $\longrightarrow$ & - \\
\hline & $1 / 200$ & . & .. & . & .. & - & - & - & ${ }^{2}$ & - & \\
\hline
\end{tabular}




\section{Conclusiones.}

De esta serie de experiencias, se deducen las siguientes conclusiones:

1. El Lisozima contenido en las deposiciones del recién nacido, tiene acción lítica evidente soḅe la Salmonella paratyphi A.

2. E: grado de actividad es directamente proporcional a la concentración y al tiempo de contacto.

3. Al $1 / 10$ se produce lisis parcial en forma instantánea, la que se hace total después de 6 horas de contacto.

4. A1 $1 / 20$ su acción empieza a ejercetse a las 3 horas y no llega a ser completa aún después de 24 horas.

5. A mayores diluciones, el extracto de deposiciones no demostró ningún efecto sobre la Salmonella paratyphi $\mathbf{A}$.

\section{CUADRO N." 6}

Acción del Lisozima contenido an las deposiciones del tecién nucido sobre el Strcptocorcus faecalis.

\begin{tabular}{|c|c|c|c|c|c|c|c|c|c|c|}
\hline \multirow{2}{*}{$\begin{array}{c}\text { Muestita } \\
\text { N. }{ }^{9}\end{array}$} & \multicolumn{4}{|c|}{ Extr. Peposic. } & \multicolumn{6}{|c|}{$\begin{array}{c}\text { Tiempo de contacto en horas e interpretación } \\
\text { de los resultados. }\end{array}$} \\
\hline & & & & . & Instant. & 3 & 6 & 12 & 18 & 24 \\
\hline & & & & & & & & & \multicolumn{2}{|c|}{, } \\
\hline \multirow[t]{5}{*}{12137} & $1 / 10$ & .. & .. . & .. . . & - & - & - & $\rightarrow$ & + & + \\
\hline & $1 / 20$ &.. &.. & $\because \quad$. & - & - & - & - & - & 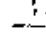 \\
\hline & $1 / 50$ &.. & ... &.. & 一 & - & - & - & - & $\ldots$ \\
\hline & $1 / 100$ &.. & .. . & .. . & - & - & - & - & - & - \\
\hline & $1 / 200^{\circ}$ & .. & . . & . . & - & - & - & - & $\cdots$ & $\ldots$ \\
\hline \multirow[t]{5}{*}{12138} & $1 / 10$ &.. & $\cdots$ & .. & 一 & - & - & - & - & - \\
\hline & $1 / 20$ &.. & .. . & .. & - & - & 一 & 一 & - & $\cdots$ \\
\hline & $1 / 50$ &.$\cdot$ & .. . & . & - & 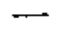 & - & - & 一 & -7 \\
\hline & $1 / 100$ &.$\cdot$ & .. . & .. & - & - & $\rightarrow$ & - & - & - \\
\hline & $1 / 200$ &.. & . & ... & - & - & - & - & -- & - \\
\hline \multirow[t]{5}{*}{12139} & $1 / 10$ & $\cdot \cdot$ & . & $\cdots$ & - & - & - & - & - & $\rightarrow$ \\
\hline & $1 / 20$ & .. & $\cdot \cdot$ & * * & - & 一 & - & - & + & + \\
\hline & $1 / 50$ & $\because$ & $\cdots$ & $=$ & - & - & $\overline{-}$ & - & - & - \\
\hline & $1 / 100$ & " & ". & . & 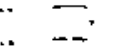 & - & $\overline{-}$ & - & $\because$ & - \\
\hline & $\begin{array}{l}1 / 200 \\
1 / 10\end{array}$ & $\ddot{*}$ & $"$. & ". & - & - & 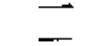 & 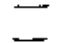 & $\overline{1}$ & - \\
\hline \multirow{4}{*}{12140} & $\begin{array}{l}1 / 10 \\
1 / 20\end{array}$ & $\ddot{.}$ & $\begin{array}{l}. . \\
. .\end{array}$ &. & - & - & - & $\overline{-}$ & \pm & + \\
\hline & $1 / 50$ & .. & .. & . . & - & - & - & - & 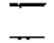 & - \\
\hline & $1 / 100$ & .. & .. & . . & 一 & 一 & - & - & $\ldots$ & $=$ \\
\hline & $1 / 200$ & .. & .. . & . . & . $\quad-$ & - & - & - & - & 一 \\
\hline
\end{tabular}




\section{Conclustones.}

En esta serie de experiencias, nos hemos encontrado con dificultades técnicas, prácticamente insalvables, por lo que nuestras conclusiones serán sólo transitorias, quedando supeditadas a estudios posteriores. Las dificultades se refieren especialmente al hecho de que los cultivos en placas de esta especie microbiana, dan colonias pequeñísimas y de aspecto transparente, muy difíciles de apreciar aún con ayuda de Iupa. En todo caso, como se desprende del cuadro, parece que el Lisozima tiene una acción muy débil scbre esta germen.

\section{CUADRO N.: 7}

Acción del Lisozima sontenido en las depasiciones del recién nacido sobrz el Proteus morganii.

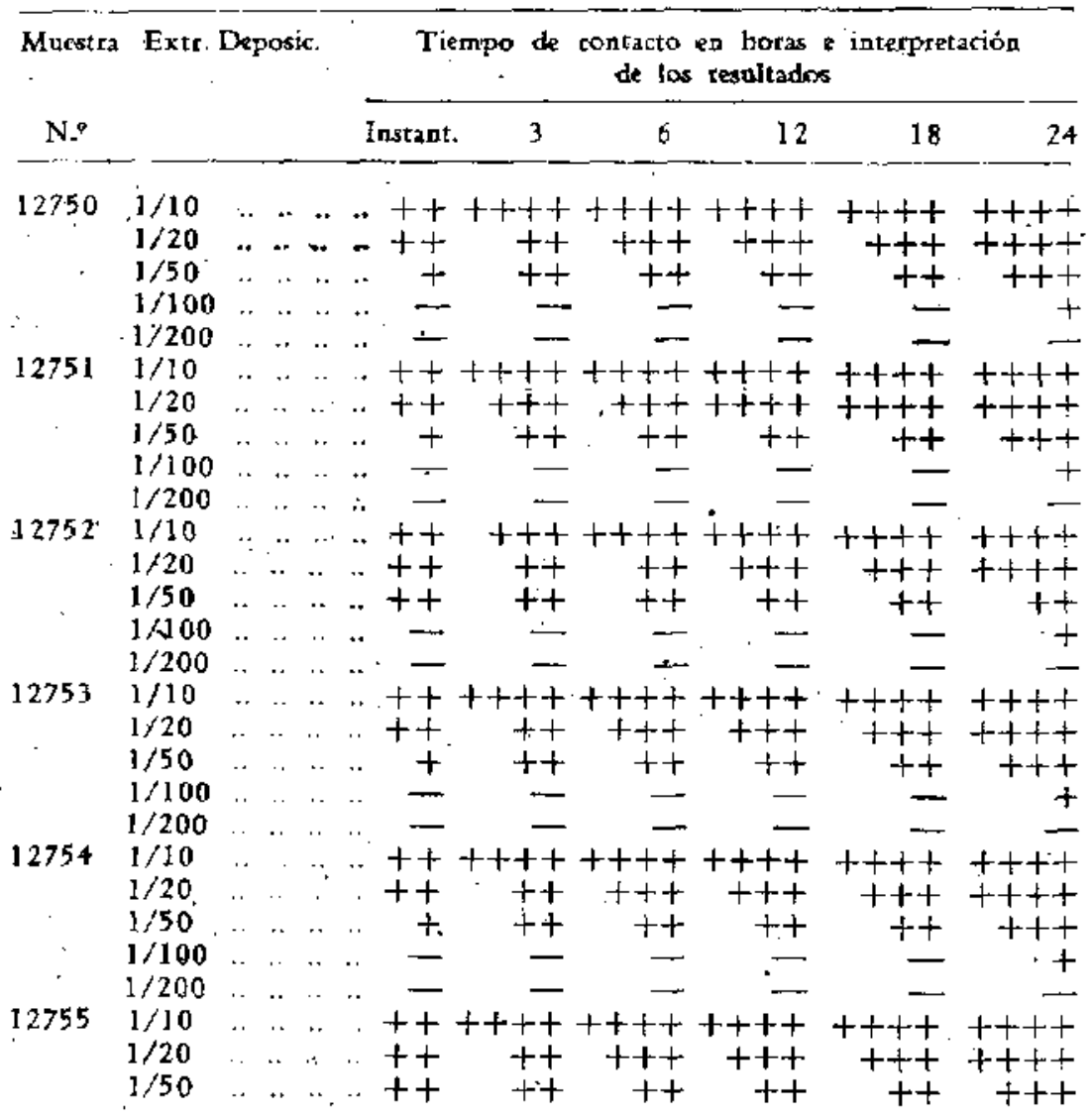


Mestra Extr. Deposic. Tiempo de contacto en boras e interpectación de los resultados

N.'

\begin{tabular}{llllll}
\hline Instant. & 3 & 6 & 12 & 18 & 24
\end{tabular}

$12758 \quad 1 / 10$

$1 / 100$

$1 / 200$

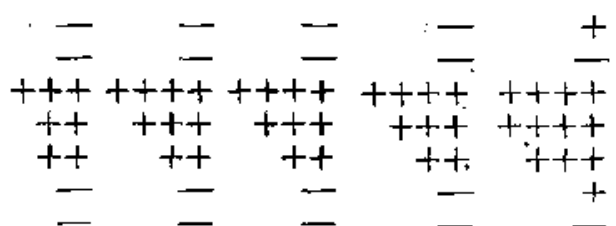

$1 / 200$

$1 / 10$

$$
\begin{array}{r}
-\bar{t} \\
+t \\
+
\end{array}
$$

$1 / 20$

$\underline{-1}$

$++t+$

$$
++
$$

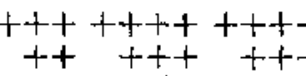

$+++t$

$1 / 20$

$1 / 50$

$+$

$++$

$+++++++t$

$1 / 100$

- -

$-$

$++++$

$++$

$1 / 20$

$1 / 50$

$+$

$1 / 100$

$1 / 200$

12759

$1 / 10$

+
+
+

$1 / 50$

$1 / 100$

$1 / 200$

Conclustones.

De esta serie de experiencias, se deducen las siguientes condlusiones:

1. El Lisozima contenido en las deposiciones de! recién nacido. tiene acción inhibidar lítica evidente sobre e] Proteus morganii.

2. El grado de actividad es directamente proporcional a la concentración y al tiempo de contacto.

3. Al $1 / 10$ se produce lisis parcial en forma instantánea. la que se hace total después de 3 horas de contacto.

4. Al $1 / 20$ su acción también se ejerce en forma instantánea. haciéndose la lisis total a las 24 horas de contacto.

5. A1 1/50 se produce lisis parcial en forma instantánea, la que no llega a hacerse completa aún después de 24 horas de cantacto.

6. . Al $1 / 100$ se manifiesta una pequeña acción líticoinhibidora, después de 24 horas de contacto. 


\section{CUADRO N. 8}

Acción del Lisozima contenido en las deposiciones del recién nacido sobre la Sbigella paradysenterize.

\begin{tabular}{|c|c|c|c|c|c|c|c|c|c|}
\hline \multirow{2}{*}{$\begin{array}{l}\text { Muestra } \\
\text { N. }\end{array}$} & \multirow[t]{2}{*}{ Extr. } & \multirow[t]{2}{*}{ Deposic. } & \multicolumn{7}{|c|}{$\begin{array}{c}\text { Tiempo de sontacto en hords e interpretación } \\
\cdot \text { de los resultados }\end{array}$} \\
\hline & & & Instant. & 3 & 6. & 12 & 18 & & 2 \\
\hline \multirow[t]{5}{*}{12755} & $1 / 10$ & $\begin{array}{llll}\therefore & . . & . .\end{array}$ & - & - & - & $\ldots$ & - & & \\
\hline & & $\begin{array}{llll}. . & . .\end{array}$ & - & - & - & -- & - & & \\
\hline & $1 /$ & $\begin{array}{lllllllll}. . & . . & . .\end{array}$ & - & - & - & - & - & & \\
\hline & & .. $\quad . . . .$. & $. . \quad-$ & - & $\div$ & - & - & & \\
\hline & $1 /$ &..... &..$\quad \rightarrow$ & - & 一 & - & - & & \\
\hline \multirow[t]{5}{*}{12756} & 1) & .. $\quad \therefore \quad .$. & $. . \quad-$ & - & - & - & - & & \\
\hline & & $\because \ldots$ & $\cdots \quad-$ & - & - & - & - & & \\
\hline & $1 / 1$ & $\begin{array}{llll}. . & \text {.. } & . .\end{array}$ & $. . \quad-$ & - & - & - & - & & \\
\hline & & $\begin{array}{lll}n^{\prime} & \because\end{array}$ & $\therefore \quad-$ & 一 & - & - & - & & \\
\hline & & $\begin{array}{lll}. & \ldots & \ldots\end{array}$ & $\therefore \quad-$ & 一 & -- & - & - & & \\
\hline \multirow[t]{5}{*}{12757} & $1 /$ & $\begin{array}{lll}. . & . .\end{array}$ & $. . \quad-$ & $\div$ & 一 & - & - & & \\
\hline & & $\begin{array}{lll}. . & . .\end{array}$ & $. \quad-$ & 一 & - & - & - & & \\
\hline & 11 & $\begin{array}{lll}. * & . .\end{array}$ & - & 一 & - & - & - & & \\
\hline & & $\begin{array}{lll}. . & . . & . .\end{array}$ & $\cdot-$ & - & - & - & - & & \\
\hline & $1 / 4$ & $\begin{array}{lll}. . & . . & . .\end{array}$ & .. $\quad-$ & — & - & - & 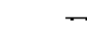 & & \\
\hline \multirow[t]{5}{*}{12758} & & & .. & - & & - & - & & \\
\hline & 11 & $\begin{array}{llll}. . & . .\end{array}$ & - & - & - & - & - & & \\
\hline & $1 /$ & $\begin{array}{llll}* & \ddots & . .\end{array}$ & $\therefore \quad-$ & - & - & $\ldots$ & - & & \\
\hline & & $\therefore \quad \therefore \quad .$. & ' ' '- & - & - & $\therefore$ & - & & \\
\hline & 11 & $\begin{array}{llll}. . & . .\end{array}$ &. & - & - & - & - & & \\
\hline \multirow{5}{*}{12759} & & $\begin{array}{lll}\ldots & \ldots & .\end{array}$ & $\cdot-$ & - & - & $\div$ & - & & \\
\hline & $1 /$ & $\begin{array}{lll}. . & . .\end{array}$ & - & - & 一 & - & - & & \\
\hline & & $\begin{array}{lll}. . & . . & . .\end{array}$ & - & - & - & -- & , & & \\
\hline & &.... & - & - & 二 & - & & & \\
\hline & $1 / 200$ & $\cdot \cdot \cdot \cdot \cdot \cdot$ & ." & - & - & - & 4 & & \\
\hline
\end{tabular}

\section{Conclusirices}

Del análisis del cuadro precedente, se desprende que la Sbigel ba paradysenteriae es altamente resistente a la acción del Lisozima fecal.

\section{CONSIDERACIONES GENERALES}

Dat presente trabajo experimental se desprende que el Lisozima se prcuentra solamente en las deposiciones de recién nacidos y lactantes que son alimentados con leche humana, ya sea en forma exclusiva o mixta.

Si consideramos ahora lis dos hechos, ya demostrados por Rosenthal y Lieberman en 1931 (28) y confirmados por nuestras recientes investigaciones, que ni el meconio de 
los recién nacidos, ni las deposiciones de les lactantes de cualquiera edad alimentados en forma artificial, contienen Lisozima, podemos deducir que este elemento presente en las-deposiciones de los niños que reciben leche humana, provenga exciusivamente de esta substancia alimenticia.

M. y J. Bordet comprobaron en 1828 (27) que, mientras el calostro y la leche humana contienen el Lisozima en alta proporción, la leche de vaca : carece de este principio. Blatt y Kesslet (34) llegarcn en 1937 a la misma conclusión. Prickett, Miller y Mc Donald (26), en 1933, sin embargo, concluyen de sus trabajos que la leche de vaca contiene Lisozima, pero, comparativamente con la leche humana, en cantidades muy reducidas. Nuestras investigaciones realizadas en la Cátedra, nos permiten confirmar los resultados obtenidos por Bordet.

Puesto que los jugos digestivos no modifican ni disminuyen el poder de este principio inhibidor-lítico, becho comprobado per Fleming y Allison (25) en 1924, el Lisozima ejercería su acción antimicrobiana en forma eficaz, a lo largo de todo é tracto digestivo del lactante.

En cuanto a los microorganismos más frecuentemente aislados del intestino y de las deposiciones de recién racidos y lactantes normales, los diferentes investigadores concuerdan en considerar al Lactobacillus bifidus como una de las especies de mayor resistencia frente al Lisozima, lo que explicarìa la frecuencia con que este germen es aislado de las deposiciones de los niños alimentados con leche humana y, al mismo tiempo, la escasez o ausencia de otra flora microbiana en estos tertenos.

Teniendo presentes las anteriores consideraciones, podemos deducir que, gracias a los recientes trabajos de Meyer, Palmer y Thompson (30), que han logrado obtener el $\mathrm{L}, \mathrm{i}$ sozima al estado de máxima pureza y aun en forma cristalizada, contamos ahora con una substancia más para combatur eficazmente ciertos procesos mórbidos digestivos del niño de naturaleza toxi-infecciosa.

\section{CONCLUSIONES GENERALES}

De nuestro estudio sobre la presencia de Lisozima en el meconio $y$ en las deposiciones de recién nacidos y lactantes $y$ de su acción inhibidora y lítica frente a algunas especies microbianas saprófitas y patógenas del tracto digestivo, se desprenden las siguientes conclusiones: 
1) En la totalidad de los casos investigados se demostró la ausencia de Lisozima en el meconio.

2) Por el contrario, se evidenció su ptesencia en todas las deposiciones de los recién nacidos alimentados con leche materna.

3) La aparición del lisozima tuvo lugar, en todos los casos controlados, en el tercer día, coincidiendo con la iniciación de' amamantamiento.

4) Los actantes alimentados con leche humana. ordeñada, demostraron contener en sus deposiciones un alto título lisozímico, semejante al que se comprobó en los niños alimentados con leche materna.

5) La edad del niño alimentado con leche humana no tiene, evidentemente, ninguna relación con el contenido lisozímico de las deposiciones.

6) La tasa lisozímica dé las deposiciones de lactantes alimentados en forma mixta, guarda relación directa con la cantidad de leche humana ingerida.

7) En los lactantes alimentados en forma artificial. no pudo demostrarse, en ningún caso, la presencia de lisozima en sus deposiciones.

8) En cuanto al poder lisozímico de las deposiciones frente a diversos gérmenes patógenos y sadrófitos del tubo digestivo, se comprobó que la intensidad de su acción varía según la especie microbiana:

a) . La Escherichia coli fué inhibida en su desarrollo en forma total por concentraciones del 1 × 10 y después de 6 horas de contacto. A concentraciones de 1 × 50 se demostró una acción muy leve después de 24 horas.

b) La Eberthella typhosa sufrió la inhibición total a concentraciones de $1 \times 10$ y después de 24 horas de contacto. A concentraciones de $1 \times 20$ se demostró, en el mismo tiempo, una acción inhibidor-lítica incompleta.

c) El Streptoccecus faecalis (entẹrococo) probó ser una especie muy resistente a la acción del lisozima fecal.

d) La Salmonella paratyphi A fué inhibida en su desarrollo en forma total por concentraciones de I $\times 10$ después de 6 horas de contacto. Al $1 \times 20$, el efecto inhibidor fué sólo parcial, aún después de 24 horas.

e) El Prcteus morganiii se reveló, de las especies microbianas estudiadas como la más sensible al lisozima fecal. A concentraciones de $1 \times 10 \mathrm{y}$ a las 3 horas de contacto, se comprobó la inhibición total de su desarrollo. Un efecto par- 
cial pudo observarse aún a concentraciones de 1 × 100 después de 24 horas.

f) La Shigella paradysenteriae (Bacilo de Flexner) se mostró altamente resistente a la acción del lisozima fecal de los recién nacidos. Concentraciones de $1 \times 10$ produjeron. después de 24 horas de contacto, sólo en algunos de los casos investigados, una inhibición parcial' de su desartollo.

\section{Bibdiografía}

1.-Topley y Wilson.- Barteriología e Inmunologia. 1:1517-1523, 1942

2.-Witkowsky, R.- Zbl. Bakt. 133:334. 1935.

3.--Schild; W.-- Z. Hyg. Infekt. Kr. 19:43, 1895.

4.-Arnold. L, ; BRODY, L.- Am. J. Hyg. 6:672, 1926.

5.-Dack. G M. y Woolpert, O.- J. Prev. Med. 6:129, 1932.

6.-Cruickshank, R.-. The Jonnal of Hygizne. 24:241-254, 1925.

7.-Tissier, H. y Dreyfus, S- Compt. Rend. Sor. Biol, 92:476, 1925.

8.--Lanter, L.- Centralblatt fïr Baktiriol, 86:579, 1921.

9.-Naujoks. H.- Centralblat fũ $\mathrm{r}$ Bakteriol. 86:579, 1921.

10.-Bachmon. A.-i- Prensa Médica Argentian. 45:2196-2202, 1939.

11.-Finketstein.- Tratado de las enfermedades del niño de pecho. 1:2, 1932 .

12.-Escherich.- Die Darnbakterien das Sauglings. 1886.

13.-Tissite. - Comt. Rend. Soc. Biol. 51:943, 1899.

14.-Tissier- Ann. Inst. Pasteur. 19:109, 1905.

15.-Moro.— J. für Kindzr. 11:697-870. 1905.

16.-Eggerth y Gagnon,- J, Bact. 25:389, 1933.

17.-Marshall L. Snyder-D. J. of Infect. Dis. 66:1-16, 1940.

18.-Nutcall, G. H. y Thierfelder- Physiol. Chem, 21:109.

19.-Cobendy, M.- Ann. Inst. Pasteur. 26:106, 1912.

20.--Rettger, L. y Cheplin, H. A. A treatise on the transformation of the intestinal flora. New Haven, [92].

21.-Cannon, P. R. y Mc. Nease. P. W.-- J. of Infizet. Dis. 32:175, 1923. 22.-Cruickthank, R-Brit. J. Exper. Path. 9:318, 1928. .

23,-Gerstley, J. R. Howell. K. L. y Nacel, B. R.- Amer. J. Dis, Child. 43:555, 1932.

24.-Fleming, A.- Prac. Roy. Soc. Series B. XClil:315, 1922.

25.-Fleming, A. and Altison. V. D.- Brit. J. Exp. 3:252, 192 ?'.

26.-Prickett. F. S.; Millec. N. Jit y Mc Donald, F. J.- J. of Bact. 25:6!, 1933.

27.-Bordet. J.-. Compt. Rend. Soc, Biol, 4:1252, 1928.

28,-Rosentbal, I. y Lieberman. H.- J, of Infect. Dis. 48:226, 1921 .

29.-Wolff. L. K.- Zitschr, fïr Inmunitietsforsch, u. exper. Tberap, 50: $88,1927$. 
30.-Meyer, K.; Palmet. J. W. Y Thompson, R. J.- J. Biol, Chemistry, 113: 303-309, 1936 .

31.--Roberts, E. A- Quart. J. Exper. Phisiol. 27:89, 1937.

32.-Xbraham, E. P.--Biocb, Journa1. 33.622-629. 1939.

33.-Hallaner, G.- Zentr. Bakt. Abt. Orig. 114:519. 1929.

34.-Meyer, K., Palmer, J. W., Thompson, R.- J. Biol. Chremistry. 113: 479-486, 19:6.

35.-Epstein, L. A. and Chain, E.- Brit. J. Exper. Pattbol. $21: 339,1940$ i.

36.--Vaccazo. H.- Bacteriología e Inmunología, 1937.

37.-Cabezas, J. y Rubina, M- Contribución al estudio del Lysozyria. Anaks de Química y Farmacia. 1942.

38.-Bergey.- Manual of Determinative Bacteriology, 1939. 